\title{
Experience of cyclone Gonu in the Islamic Republic of Iran: lessons learned
}

\author{
F. Panahi, ${ }^{1}$ R. Asadollahi, ${ }^{2}$ M. Asadollahi ${ }^{3}$ and A. Hasani-Bafarani ${ }^{4}$
}

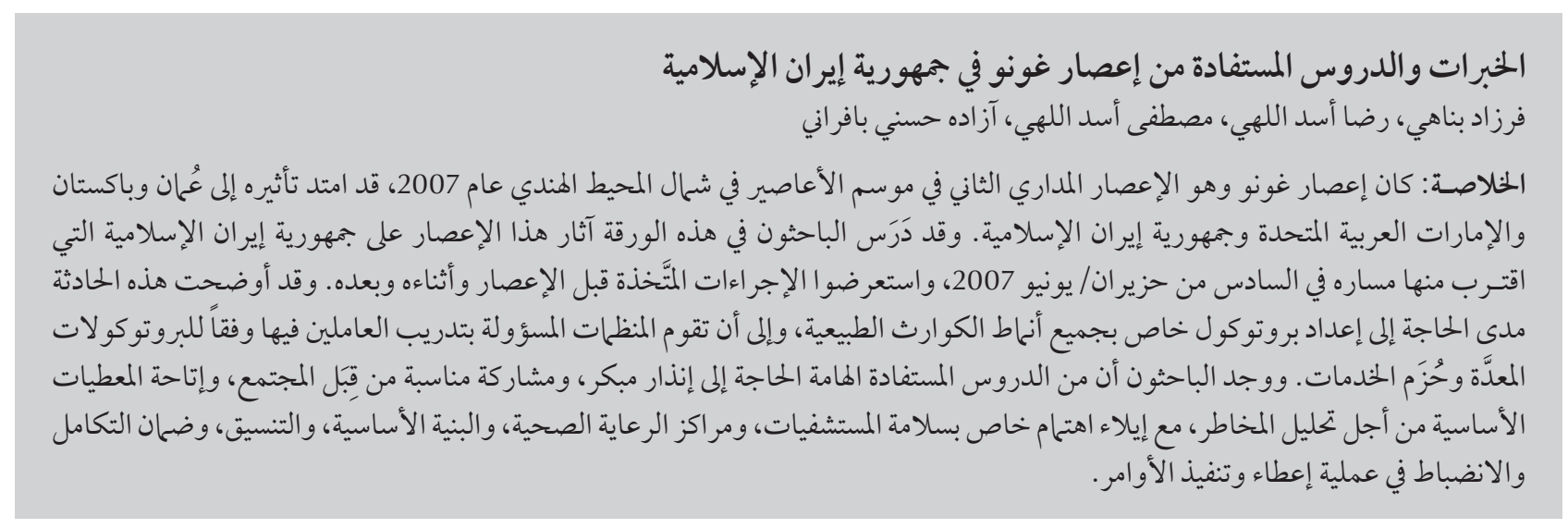

ABSTRACT Gonu, the second tropical cyclone of the 2007 northern Indian ocean cyclone season, affected Oman, Pakistan, the United Arab Emirates and the Islamic Republic of Iran. This report examines the effects of cyclone Gonu in the Islamic Republic of Iran where it approached on its path on 6 June 2007 and reviews the actions taken before, during and after the cyclone. The incident highlighted the need for a special protocol to be prepared for all types of natural disasters. Responsible organizations should train their personnel according to the prepared protocols and service packages. Among the important lessons learned were the need for early warning, proper community involvement, access to essential data for risk analysis, special attention to safety of infrastructures, coordination and command integrity.

\section{Passage du cyclone Gonu dans la République islamique d'Iran : enseignements tirés de cette expérience}

RÉSUMÉ Gonu, le deuxième cyclone tropical de la saison des cyclones de l'année 2007 du nord de I'océan Indien, a frappé les Émirats arabes unis, la République islamique d'Iran, le Pakistan, et le Sultanat d'Oman. Le présent rapport étudie les effets du cyclone Gonu en République islamique d'Iran, qu'il approcha dans sa course le 6 juin 2007, et analyse les actions entreprises avant, pendant et après le passage du cyclone. L'incident a mis en lumière le besoin d'un protocole spécial pour la préparation à tous les types de catastrophes naturelles. Les organisations concernées devraient former leur personnel en suivant les protocoles et les ensembles de services préparés. Parmi les enseignements importants tirés de cette expérience, nous pouvons citer les suivants : le besoin d'une alerte précoce, d'un engagement adéquat de la communauté, d'un accès aux données essentielles pour l'analyse des risques, d'une attention particulière à la sécurité des hôpitaux et des centres de soins de santé, mais aussi le besoin d'infrastructures, de coordination des niveaux hiérarchiques et d'intégrité à ces niveaux. 


\section{Introduction}

Cyclones, hurricanes and typhoons are intense low-pressure weather systems arising in the tropics that produce strong winds and heavy rain. These storms are the most damaging large-scale weather systems in the world and cause massive destruction and loss of life [1].

Tropical cyclones occur in the south-west Pacific, south-east Indian, north Indian, south Pacific or South Atlantic oceans [1]. Gonu, the second named tropical cyclone of the 2007 northern Indian Ocean cyclone season, developed from a persistent area of convection in the eastern Arabian Sea on 1 June before rapidly intensifying to reach peak winds of $240 \mathrm{~km} / \mathrm{h}(150$ $\mathrm{mph}$ ) on 3 June according to the Indian meteorological department. Late on 5 June, it crossed the land on the easternmost tip of Oman [2]. Reports say cyclone Gonu was the strongest to hit the Arabian Peninsula since records started in 1945 [3]. The cyclone caused about US $\$ 4$ billion damage and about 50 deaths with 14 people missing in Oman, where the cyclone was considered the nation's worst natural disaster. Gonu dropped heavy rainfall near the eastern coastline, reaching up to 610 $\mathrm{mm}$ (24 inches), which caused flooding and heavy damage $[4,5]$. After affecting Oman (especially Muscat), the United Arab Emirates and Pakistan (Sindh and Baluchistan) [6], Gonu was the first cyclone to affect the Islamic Republic of Iran in almost 100 years [7].

\section{Cyclone Gonu in the Islamic Republic of Iran}

Cyclone Gonu hit the Islamic Republic of Iran on 6 June 2007, causing sea waves up to 5.8 metres and moderate to heavy rain. Gonu affected 3 provinces, Sistan va Baluchestan (especially Chabahar and Konarak), Hormozgan (Bandar Abbas, Jask, Bashagard) and southern parts of Kerman. Winds reached $111 \mathrm{~km} / \mathrm{h}$
(69 mph) and heavy monsoon rainfall (part of the seasonal pattern in the area) caused some of the rivers to overflow. The cyclone and the consequent heavy rain continued until 8 June $[8,9]$.

The cyclone affected an estimated 560000 people in 28 cities and 2900 villages. Throughout the affected areas the cyclone caused 23 deaths (20 from drowning) and more than 20000 houses were flooded. The death toll of domesticated animals was estimated to be about 6500 . The total damage in the Islamic Republic of Iran was estimated at 2 billion Iranian riyals (US\$ 216 million) [10]. Other major effects of cyclone Gonu included disconnection of electricity, piped water and telecommunications to more than 2200 population units, destruction of transport routes to more than 2000 population units, destruction of several dams [11] and damage to the shrimp-breeding industry, one of the most important industries of Chabahar and Konarak, at an estimated cost of about US\$ 6 million [12].

Climate change and increases in the incidence of storms and floods throughout the world highlights the need for a comprehensive emergency planning system capable of responding to such events. This report examines the effects of cyclone Gonu in the Islamic Republic of Iran and the measures which were taken before, during and after the cyclone.

\section{Review of the emergency response}

During the emergency response to cyclone Gonu in the Islamic Republic of Iran written logs documenting the initial actions that were taken were kept by the Natural Disaster Management Task Force of the Ministry of Interior, the Secretariat for Health Risk Management in Disasters of the Ministry of Health and Medical Education, the Secretariat of the Task Force on Meteoric
Disasters and the Iran Red Crescent Society. These log entries were reviewed for this report.

Rosters of staff who initially assisted or were deployed in the field operation were obtained. Team leaders who managed or coordinated these teams were interviewed using structured and unstructured questions.

Copies of correspondence, including health alerts, messages and situation reports were collected and reviewed for relevant content. The first author was the coordinator between the health authorities of the 3 affected provinces in charge of the health sector response and his notes and reports were also used.

A Google search was conducted for reports of different news agencies and newspapers. Additional anecdotal information or experiences were obtained from presentations at the "International meeting on Gonu cyclone: lessons learned" held on 18-19 February 2008 in Chabahar, Islamic Republic of Iran by the Secretariat for Health Risk Management in Disasters in collaboration with the World Health Organization Regional Office for the Eastern Mediterranean.

\section{Pre- and post- incident measures for management}

The experiences of the Bam earthquake, which struck the Islamic Republic of Iran in 2003, highlighted the need to improve disaster preparedness and disaster management in the country. This prompted the preparation of predisaster guidelines, some of which were utilized in the next event, the Lorestan earthquake in 2006. Thus there was a better level of preparedness for responding to upcoming emergencies (including cyclone Gonu). Actions taken for the management of cyclone Gonu can be reviewed in 2 parts: pre-incident and post-incident measures. 


\section{Pre-incident measures}

In view of the fact that Oman and Pakistan were affected by cyclone Gonu before it passed over the Islamic Republic of Iran, the relevant organizations were in a state of alert after receiving written warnings from the Iranian weather bureau on 5 June. The recipient organizations of this alert included: Ministry of Health and Medical Education, the governorships of Sistan va Baluchestan, Hormozgan and Kerman provinces; Iran Red Crescent Society; general staff of the Iranian armed forces; civil aviation department; fire department; navigation and ports authorities; Ministry of Foreign Affairs; and all related agencies of the United Nations.

The first stage - the evacuation of people from the coastlines to higher and safer places - started quickly. Mosques, sports clubs and schools were prepared to accommodate local residents who had been evacuated or lost their homes. The other major measures comprised:

- Obtaining updated information minute-by-minute about the storm conditions through Internet websites and satellite images.

- Dissemination of early warning messages through the media and local information networks.

- Transfer of passenger boats, tugboats and light and heavy rafts to safe places as well as a halt to any kind of fishing.

- Ensuring readiness of fire trucks and provincial ambulances.

- Announcing the alert phase for all reinforcement agents such as Red Crescent volunteers.

- Ensuring readiness of all hospitals, health centres and health posts in the high-risk provinces.

- Preparation of food, water and food rations for those already evacuated or those who may be in need later.

- Evacuation of Chabahar hospital (in the high-risk zone) and provision of some essential medical and general equipment in nearby safe places.

\section{Post-incident measures}

Due to proper preparation and good coordination with the general staff of the armed forces, several flights were dispatched to the region soon after the incident based on an initial assessment of personnel shortages in distributing the necessary equipment. Food, medicine and tent packages were sent to the region by the Red Crescent Society and other relevant organizations.

Reconstruction and repair of water systems, electricity, telecommunications and roads began immediately. All the main roads were opened 3 days after the incident and during this time electricity, water and telecommunication networks were reconstructed in $80 \%$ of the damaged regions.

About 2500 families were accommodated in the prepared areas and in emergency tents. Injured people were treated in the hospitals, health centres and mobile hospitals provided $[11,13]$.

Necessary policies were considered by the Iranian Center of Disease Control for prevention of the waterborne diseases (cholera, non-specific diarrhoea, rotavirus, typhoid and paratyphoid) and the vectorborne diseases (leptospirosis and malaria).

\section{Disease control and prevention prior to the cyclone}

- Attention to weather bureau warnings to predict the features of the storm and to design an appropriate, comprehensive disease control plan.

- Recruitment of all human resources relevant to disease control and application of service guidelines.

- Evaluation of the regional equipment stores required for disease control.

- Assessing the training requirements and availability of health sector staff.

- Risk assessment of public health issues, considering local conditions.

- Predicting potential risks due to loss of facilities and resources (e.g. spoil- ing of biological products such as vaccines due to electricity loss).

\section{Disease control and prevention during and after the cyclone}

- Establishment of an active disease surveillance and data collection system for daily assessment of diseases.

- Implementation of a specific surveillance system for cholera.

- Supplying safe (bottled) water in the early days after the storm to control waterborne diseases.

- Constructing hygienic toilets.

- Drying superficial ponds and swamps to prevent outbreaks of cholera and malaria.

- Face-to-face education of the public and distribution of educational pamphlets.

- Starting larval eradication 2-3 weeks after the flood.

- Hygienic burial of animal carcasses.

- Disinfection of the environment via debris removal and insecticide fogging.

- Identification of patients with diarrhoea [14].

\section{Lessons learned}

\section{Appropriate and timely early warning}

Appropriate and timely warnings before the occurrence of a disaster can reduce human and financial losses. Both civilians and responsible government organizations should be warned. During cyclone Gonu, the warnings resulted in the vacuation of the population of Chabahar and Konarak areas, and the preparation of local authorities.

\section{Managing what really happens in the field}

In the immediate aftermath of a disaster, the severity of its impact and extent of the damage should be evaluated by 
teams of experts. This assessment is essential for the prediction of needs. During the cyclone, the extent of the affected areas and inaccessibility of many villages and human settlements led to lack of accurate information about the damages and resulted in the wrong type and incorrect amount of resources being mobilized to the affected areas.

\section{Training of personnel}

A specific protocol should be prepared for all known types of natural disaster. Responsible organizations should train their personnel according to the prepared protocols and service packages. Each responsible person should be given a description of his/her own duties.

The role of volunteers should be defined too. During cyclone Gonu, confusion over duties and incorrect actions by personnel were the result of the lack of a clear written protocol. Regular training, annual exercises and public education are necessary in the disaster preparedness phase.

\section{Staying operational so that you can help}

In disaster conditions, there is always the possibility of damage to and malfunction of important infrastructures such as water supplies, electricity, telecommunication and transport routes. Thus provision of backup systems for energy and communications is a must. Cylone Gonu again highlighted the need for electricity generators, communication devices, water tanks and mobile health facilities following a natural disaster.

\section{A rescuer should not be in need of rescue}

Many health centres in the affected areas were not resilient enough to be completely operational after the cyclone. The price we pay for the failure of hospitals or health facilities in a disaster is too high; in comparison, the cost of making hospitals safe from disasters is small. Disaster damage to health systems is a human tragedy, resulting in huge economic losses, devastating blows to development goals and damage to social confidence. Ensuring that hospitals and health facilities are safe from disasters is not only an economic requirement, but also a social, moral and ethical necessity.

\section{Integrated disaster management: a repetitive experience}

Multiple lines of command that lack coordination and command integrity and limited resources are typical problems of disaster management. Ensuring the integration of disaster management systems increases their efficiency and prevents waste of time and of human and financial resources.

\section{Strengthening the health network}

A unique feature of the health system of the Islamic Republic of Iran that facilitates an efficient response to emergencies is the network of health posts and health centres. They act as censors at the community level and help gather information and provide early warning and surveillance [15]. The efficiency of this network in accessing affected people, fast response to health issues and providing services was a key factor in the response to cyclone Gonu, especially at the areas where access was initially a problem.

\section{Conclusions}

Every country should have a national policy for the management of disasters and emergencies. This policy should be documented by the government and mandated to all organizations having responsibilities in disaster management to enable them to develop their own disaster management plan as a part of the national disaster management plan.

Key points which should be highlighted in these plans include the duties and responsibilities of the organization, human resources and logistics, preparation of suitable guidelines, secretariat or coordination unit, coordination mechanisms between key ministries and special attention to improvements in communications, transport and the health infrastructure.

Public education for appropriate community involvement in different phases of disaster management should not be forgotten.

\section{References}

1. Coenraads R. Natural disasters and how we cope. Elanora Heights, Australia, Millennium House, 2006:179-217.

2. Tropical cyclone Gonu. Earth observatory, NASA [website] https://earthobservatory.nasa.gov/NaturalHazards/quarterly.php?cat_id=10\&y=2007\&q=2, accessed 20 September 2010).

3. Cyclone hits Gulf state of Oman. BBC news [website] (http:// news.bbc.co.uk/2/hi/6722749.stm

4. Cyclone Gonu. Wikipedia [website] (http://en.wikipedia.org/ wiki/Cyclone_Gonu, accessed 20 September 2010).

5. Azhar Haroun A. L-Kindi. Gonu: lessons learnt. Presentation to the International meeting on Gonu Cyclone: lessons learned, 18-19 February 2008, Chabahar, Islamic Republic of Iran.
6. Federal Ministry of Health, Government of the Islamic Republic of Pakistan. Warning phase activities and lessons learned. Presentation to the International meeting on Gonu Cyclone: Lessons Learned, 18-19 February 2008, Chabahar, Islamic Republic of Iran.

7. Gonu cyclone reached Iran coasts [in Farsi]. Roshangari [website] (www.roshangari.net/as/ds.cgi?art=20070715032601.html, accessed 20 September 2010).

8. Cyclone Gonu kills 15. Gulfnews.com [website] (http://archive. gulfnews.com/region/oman/10130666.html, accessed 20 September 2010).

9. Iranevacuatesthousandsascyclonestrikes.ABCnewsonline[website] (http://www.abc.net.au/news/newsitems/200706/ s1944500.htm, accessed 20 September 2010). 
10. Death toll in Iran from cyclone climbs to 23. Reuters [website] (http://www.alertnet.org/thenews/newsdesk/L10319787. htm, accessed 20 September 2010).

11. Iran Weather Bureau. [Super cyclonic storm Gonu]. Final report of the Secretariat of the Task Force on Meteoric Disasters, July 2007 [in Farsi].

12. [Gonu cyclone damage to shrimp breeding]. Farmiran [website] (www.farmiran.ir/news/?id=3415, accessed 20 October 2010) [in Farsi].
13. [Comprehensive report of the Secretariat for Health Risk Management in Disasters about the Gonu cyclone]. Tehran, Ministry of Health and Medical Education, 2007 [in Farsi].

14. Soroush M. A report of the learnt lessons from Gonu flood regarding disease control and prevention aspects. Presentation to the International meeting on Gonu Cyclone: Lessons Learned, 18-19 February 2008, Chabahar, Islamic Republic of Iran.

15. Bristol N. US region to model health service on Iranian system. Lancet, 2010, 375(9715):625.

\section{Natural Hazards, UnNatural Disasters: The Economics of Effective Prevention}

According to this joint report from the World Bank and the United Nations, annual global losses from natural disasters could triple to $\$ 185$ billion by the end of this century, even without calculating the impact of climate change. Climate change could then add \$28-\$68 billion more in damages each year from tropical cyclones alone. The report also says that the number of people exposed to storms and earthquakes in large cities could double to 1.5 billion by 2050 .

The report outlines a number of measures to prevent death and destruction from natural hazards such as earthquakes, hurricanes, and flooding. For example, governments can make information about hazards and risks easily accessible. Providing land titles reduces the possibility of eviction or demolition, and encourages individuals to invest in safer structures; removing rent controls restores incentives for landlords to maintain buildings; and reorienting existing public spending to prioritize day-to-day operations and maintenance would increase prevention. Undertaking these measures does not necessarily require governments to spend more, says the report, but to spend better.

The report emphasizes that it is the vulnerable, not the rich, who face the brunt of natural hazards There were 3.3 million deaths from natural hazards in the 40 years to 2010. Damages are disproportionally high in middle-income countries. One area where the report calls for more spending is on early warning systems, particularly weather forecasting. There have been many advances in predicting weather, with three-day accuracy now over 95 per cent and more than half the seven-day forecasts correct. Few countries, however, have taken full advantage of this progress since many governments do not fund their hydro-meteorological services adequately.

The report can be accessed at: http://www.gfdrr.org/gfdrr/sites/gfdrr.org/files/nhud/files/NHUD-Report_Full.pdf 